\title{
ESTIMATION AND MEASUREMENT OF THE AUTOMOBILE POLLUTION: APPLICATION TO BEJAIA CASE
}

\author{
R. ALKAMA ${ }^{1, *}$ \\ F. AIT-IDIR ${ }^{2}$ \\ Z. SLIMANI ${ }^{2}$
}

Received: 21/02/06

Accepted: 30/06/06

\author{
${ }^{1}$ Laboratoire de Génie Electrique \\ ${ }^{2}$ Département d'écologie \\ University of Béjaia, 06000 Bejaia, Algeria
}

\begin{abstract}
In this paper, we present the estimate and results of measurement of air pollution in Béjaia city in Algeria.

We used an enclosure of $0,80 \mathrm{~m}^{3}$ for the collection of gases directly on the outlet side of the tailpipe of the vehicles. A three-gas detector (MX21 plus), introduced inside the enclosure, measures the rates of carbon monoxide $\mathrm{CO}$, sulphur dioxide $\mathrm{SO}_{2}$ and nitric monoxide $\mathrm{NO}$. We studied the exhaust pollutants according to the age of the vehicle $(1980-2004)$ and the acceleration of the engine. Measurements related to a sample of 204 vehicles using gasoline or diesel oil fuel.
\end{abstract}

The comparison between the rejections and the standards European, American and Japanese norms encourages us to challenge the authorities on the urgency of the introduction of the vehicle inspection and technical control. Except the new vehicles (less than 5 years old), where the results are comparable, the others exceed largely the standards.

We have counted the number of vehicles passing through the Daouadji square during one month (March 2004) and calculated the total pollution rejected. The comparison with the air pollution measured in situ confirmed that urban pollution is primarily from automobile sources. On the curve of the weekly evolution of the air pollution the days and peak hours of the automobile traffic appear clearly. The correlation with the number of vehicles is very significant $(0,78)$.

By taking account of the annual rate of increase in the number of vehicles and keeping the current park without adequate maintenance, a statistical model envisages an unbearable urban pollution near 2010.

KEYWORDS: automobile pollution, standards of emission, fuel type.

\section{INTRODUCTION}

Air pollution in urban areas has become a very important phenomenon [1]. Atmospheric pollution has a harmful impact on health. Automobile traffic is one of the important source of this pollution [2]. In urban areas, the motor vehicle contribution to carbon monoxide pollution can exceed 90 percent [3]. Most countries consider this problem a threat of the national health, and make strict regulations to reduce it as much as possible. Several studies carried out showed a great correlation between the strong levels of air pollution and the death rate by respiratory and cardiovascular problems. The last years have shown an increase in public and government concern around air quality in urban cities. In urban areas, automobile exhaust emissions are more important in intersections of roadways, traffic jam and narrow streets [4]. So we chose an intersection for our companion of measurements and study diurnal and weekly evolution of pollutants.

After a short recall of the principal pollutants of automobile origin, we present the measurement results of pollution in Béjaia city (Algeria) carried out in March 2004. Bejaia is a coastal town in algeria with an area of about $10 \mathrm{~km}^{2}$ and has a population of 200000 growing 
at the rate of $2,1 \%$. Measurements of the forward thrusts of the vehicles according to the age, the fuel type and acceleration can inform about emissions contributions.

\section{POLLUTANTS EMITTED BY MOTOR VEHICLES}

The motor vehicles reject into the atmosphere significant quantities of carbon monoxide (CO), hydrocarbons $\left(\mathrm{C}_{\mathrm{x}} \mathrm{H}_{\mathrm{x}}\right)$, nitrogen oxides $\left(\mathrm{NO}_{\mathrm{x}}\right)$, fine particles, suffer dioxide $\left(\mathrm{SO}_{2}\right)$, lead and support the ozone $\left(\mathrm{O}_{3}\right)$ formation.

- The carbon monoxide is a colourless, odourless and insipid gas produced by the incomplete combustion of hydrocarbons. $\mathrm{CO}$ penetrates in blood by the lungs, combines with haemoglobin 200 times more easily than oxygen and thus deteriorates the transport of oxygen towards the bodies. $\mathrm{CO}$ is a product of incomplete combustion of hydrocarbonbased fuels.

- Nitrogen oxides are highly reactive gases, toxic and irritating the lungs. Their formation is favoured by high temperatures and excess oxygen.

- Hydrocarbons are emitted mainly from gasoline engines, hydrocarbon pollution results when unburned or partially burned fuel is emitted from the engine as exhaust, and also when fuel evaporates directly into the atmosphere. They contain toxic compounds and cause cancer.

- The fine particles in suspension come mainly from the smoke of the diesel

- Engines and worsen the respiratory diseases.

- Suffer dioxide is a colourless and non flammable gas produced by the combustion of suffers residual in the fuels.

- Lead comes mainly from the combustion of the additives to lead contained in the gasoline. It is at the origin of neurological, haematological and renal disturbances.

- Ozone is formed by the action of the solar radiation and heat on nitrogen oxides and hydrocarbons. It is irritating for the respiratory system and the mucous ocular membranes.

Acceptable limits for each pollutant are fixed by the WHO [5].

\section{URBAN AIR POLLUTION IN BEJAIA CITY}

In a preceding study [6], we measured pollution in several sites of Béjaia city and found that the maximum of pollution is near Amriw and Daouadji crossroads.

To emphasise the share of the automobile traffic in the air pollution, we measured the concentrations of 3 pollutants $\left(\mathrm{CO}, \mathrm{NO}\right.$ and $\mathrm{SO}_{2}$ ) and counted the number of vehicles passing by Daouadji square. We used an exhaust three-gas analyser MX21 PLUS which is available at bejaia university laboratories. It is placed on the pavement at two meters from the roadway and one meter height. Measurements are raised each five minutes from $7 \mathrm{~h} 30$ to $18 \mathrm{~h} 30$. The concentrations of $\mathrm{NO}$ and $\mathrm{SO}_{2}$ are relatively weak, we exploited only $\mathrm{CO}$ measurements during all march 2004.

According to the four weeks, Monday was the most polluted because of the weekly market and sportive and cultural activities in the afternoon.

Figure 1 shows the linear regression curve between measured CO concentration in ppm and the number of vehicle passing across Daouadji square. Measurements are made each 10 minutes on Monday 22 march 2004. The correlation is very significant with a coefficient of 0,78 .

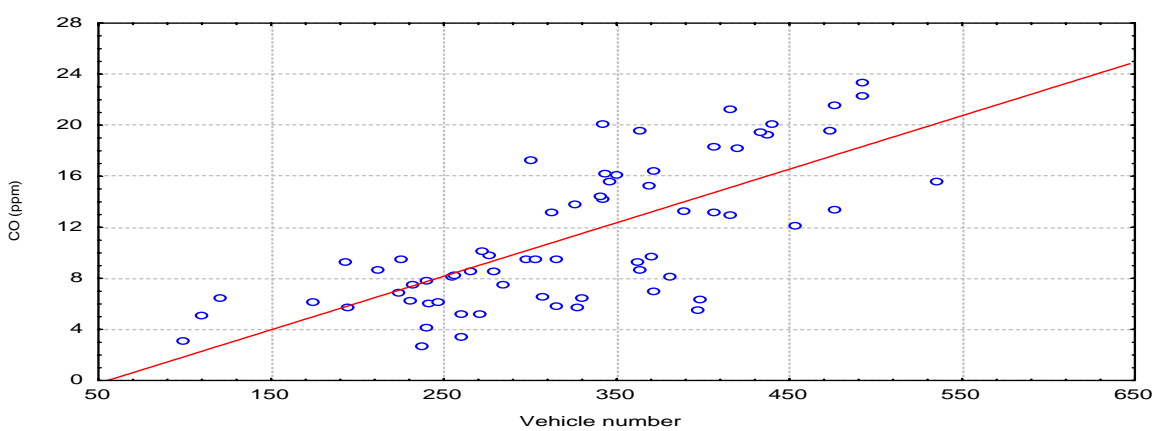

Figure 1. Regression curve between $\mathrm{CO}$ concentration and vehicle number 
This strong correlation means that measured pollution come principally from automobile traffic. We can notice that the measured concentrations of $\mathrm{CO}$ are comparable with those measured in other European cities and remain less than the recommended limits.

\section{MEASUREMENT OF EXHAUST PIPE GASES}

In order to ring automobile pollution, we measured the concentrations of three pollutants ( $\mathrm{CO}$, $\mathrm{NO}$ and $\mathrm{SO}_{2}$ ) directly on the exhaust pipe exit. We used two methods of measurements and ended roughly to the same results. In the first, one measures the flow Q = V.S by the measurement of the velocity $\mathrm{V}$ using an anemometer and surface $\mathrm{S}$ starting from the exit pipe diameter. In the second one, the apparatus is introduced inside a transparent enclosure of volume $0,8 \mathrm{~m}^{3}$. The pollution rejected by the pipe is entirely collected in the enclosure during 10 seconds and there remains preserved. This method enables us to carry out 10 measurements of the same concentration and than take the average. Our interest is pollution variation according with fuel type (gasoline or diesel), the age of the vehicles ( 0 to 24 years) and with acceleration (weak, average or great).

\subsection{Diesel vehicles}

Data from 54 several types of vehicles was gathered in Bejaia area. Vehicles were divided into 9 groups according to the age of the vehicle (1987-1988), (1989-1990), (2003-2004). A number of 6 cars of each group were tested and average of pollutant concentrations are considered. Figure 2 shows concentrations of $\mathrm{NO}$ and $\mathrm{CO}$ according to the age of the vehicle and for three accelerations : weak (slow-down), middle and maximum.
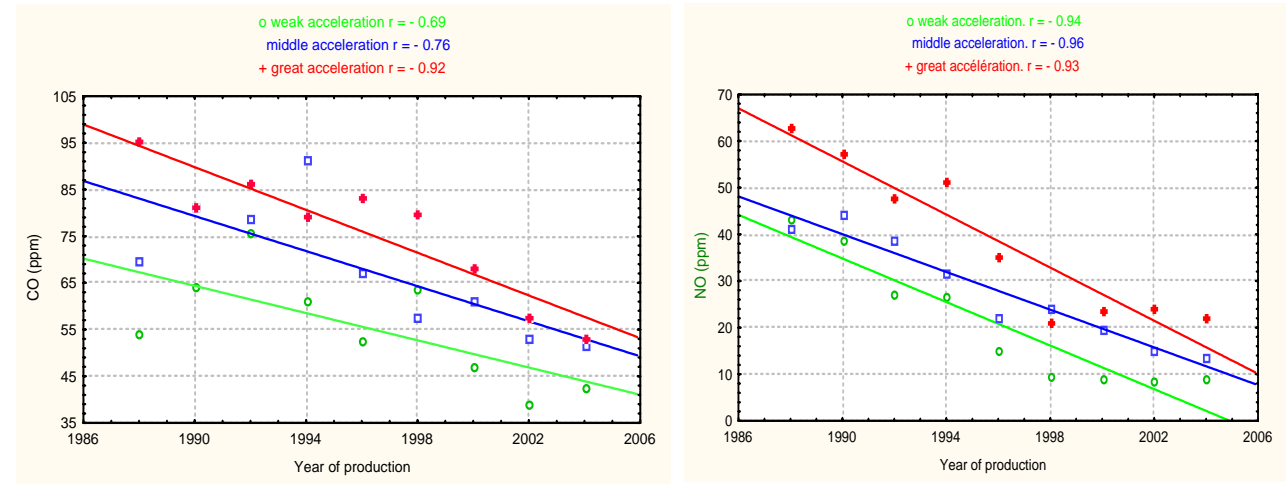

Figure 2. $\mathrm{CO}$ and NO emissions versus vehicle age for 3 accelerations in diesel vehicles

Tests are made in hold-stabilised conditions. There is a very important correlation between concentration of emitted pollutants and the vehicle age. In other side, pollutants increase with acceleration because of great consumption.

\subsection{Gasoline vehicles}

The measurements are made with 150 several types of vehicles. They were divided into 12 groups according to the age of the vehicle (1981-1982), (1983-1984), (2003-2004). A number of 8 cars of each group were tested and average of pollutant concentrations are considered. Figures 3 shows emissions of $\mathrm{NO}$ and $\mathrm{CO}$ according to the year of production of the vehicle and the acceleration. 

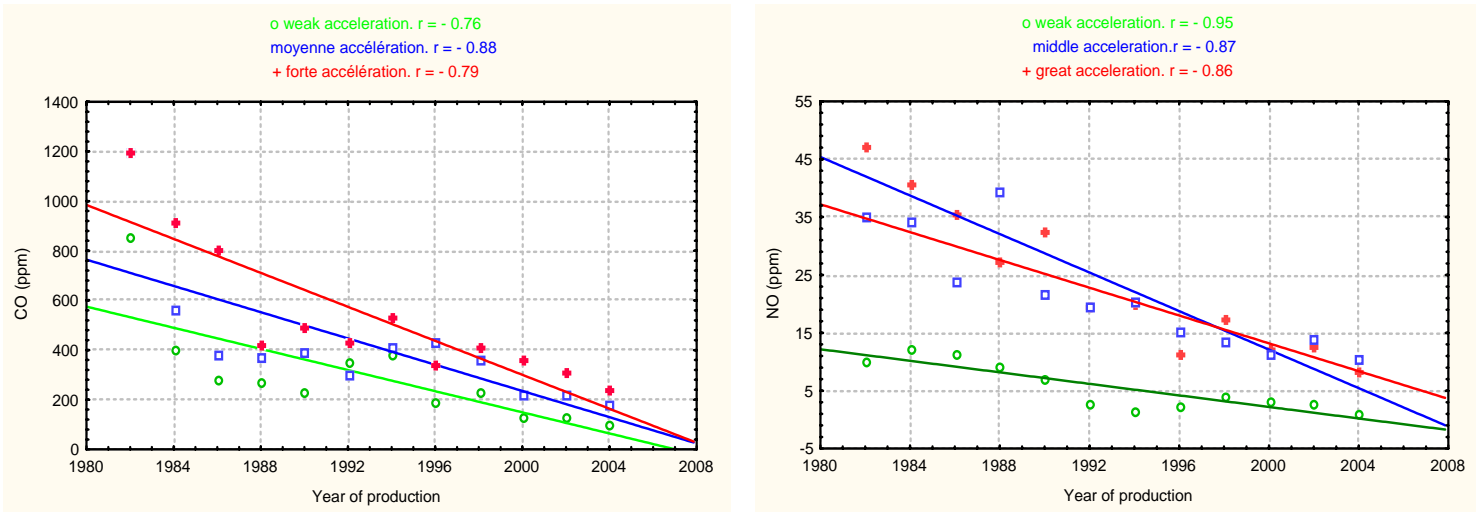

Figure 3. $\mathrm{CO}$ and $\mathrm{NO}$ emissions versus vehicle age for 3 accelerations in gasoline vehicles

For the old cars, CO emission reaches apparatus saturation (1200 ppm). Regression results are very significant. The correlation is more important when the vehicle is so old. For the three last groups the decrease of $\mathrm{CO}$ and $\mathrm{NO}$ are due to the use of exhaust gas recirculation (EGR).

$\mathrm{SO}_{2}$ emission is note represented because it is weak for diesel vehicles and negligible for gasoline cars.

\subsection{Comparison with the international standards}

After many years effort, the United States of America, Europe and Japan arrived to attenuate air pollution problems by the introduction of anti-pollution techniques such as catalytic converter appeared in 1985 and the unleaded gasoline generalised in 2000. With imposed limits, reductions from 50 to $400 \%$ of emissions were achieved in the last five years [7].

To be able to compare our results with these standards, we must express the rates of pollution in $\mathrm{g} \mathrm{km}^{-1}$. The average speed inside urban cities is estimated at $30 \mathrm{~km} \mathrm{~h}^{-1}$. So it is assumed that 120 seconds are necessary for a car to travel $1 \mathrm{~km}$.

For $\mathrm{CO}\left(1 \mathrm{ppm}=1,15 \mathrm{mg} \mathrm{m}^{-3}\right)$, the measurement of $1 \mathrm{ppm}$ in the enclosure of $0,8 \mathrm{~m}^{3}$ during 10 seconds is equivalent to $9,6610^{-3} \mathrm{~g} \mathrm{~km}^{-1}$. For $\mathrm{NO}\left(1 \mathrm{ppm}=1,23 \mathrm{mg} \mathrm{m}^{-3}\right), 1 \mathrm{ppm}$ is equivalent to $10,3310^{-3} \mathrm{~g} \mathrm{~km}^{-1}$ while for $\mathrm{SO}_{2}\left(1 \mathrm{ppm}=2,86 \mathrm{mg} \mathrm{m}^{-3}\right), 1 \mathrm{ppm}$ is equivalent to $24,0210-3 \mathrm{~g} \mathrm{~km}^{-1}$. The results of the emissions measured in $\mathrm{g} \mathrm{km}^{-1}$ for the middle acceleration of diesel (D) and gasoline (G) vehicles are gathered in table 1.

Table 1. Measured $\mathrm{CO}$ and $\mathrm{NO}$ emissions in $\mathrm{g} \mathrm{km}^{-1}$ according to the vehicle age and the fuel type. American, Japanese and European standards are also presented [7]

\begin{tabular}{|c|c|c|c|c|c|c|c|c|c|c|c|c|c|c|c|c|c|c|}
\hline & \multicolumn{2}{|c|}{\begin{tabular}{|l|}
$80-84$ \\
\end{tabular}} & \multicolumn{2}{|c|}{ 84-88 } & \multicolumn{2}{|c|}{$88-92$} & \multicolumn{2}{|c|}{$92-96$} & \multicolumn{2}{|c|}{ 96-00 } & \multicolumn{2}{|c|}{$00-04$} & \multicolumn{2}{|c|}{ USA 04} & \multicolumn{2}{|c|}{ Japan 02} & \multicolumn{2}{|c|}{ EU 05} \\
\hline & $\mathbf{G}$ & $\mathbf{D}$ & $\mathbf{G}$ & D & $\mathbf{G}$ & D & $\mathbf{G}$ & D & $\mathbf{G}$ & D & $\mathbf{G}$ & D & $\mathbf{G}$ & D & $\mathbf{G}$ & D & $\mathbf{G}$ & D \\
\hline CO & 8.5 & & 3.6 & & 3.3 & .77 & 4.1 & .77 & 2.8 & .57 & 1.9 & .54 & 1.1 & 1.1 & 67 & .63 & 1 & .50 \\
\hline NO & .36 & & .33 & & .21 & .43 & .18 & .33 & .13 & .32 & .12 & .12 & .04 & .04 & .08 & .28 & .08 & .25 \\
\hline
\end{tabular}

We notice that the emissions of the recent vehicles $(2000-2004)$ are comparable with the European standards but for the oldest vehicles, the emissions are much more important. It appears that periodic and obligatory technical vehicle inspection must be established in Algeria.

For the other pollutants, the restrictions are applied to the fuels. The unleaded gasoline is generalised since January 2000 in Europe. For example the maximum suffers content in diesel oil brought back from 450 ppm in 1999 to 50 ppm in 2005.

\section{ESTIMATED AND MEASURED POLLUTION}

Automobile park in Bejaia department increase from 11285 in 1970 to 105647 in january 2005 with an average rate of $15.7 \%$. From data of registered vehicles in Bejaia (including year production and fuel type to find percentage of each group) and measured emissions found in table 1, we have calculated CO concentration depending on the number of vehicles passing through Daouadji square, wind direction and wind speed. 
Figure 4 shows CO concentrations estimated and measured in Monday 22 march 2004 near Daouadji square. On the layout appear clearly the peak hours where the automobile traffic is intense. The difference between measured pollution and estimated one may be explained by dispersion disturbance caused by vehicle motion and other meteorological parameters not considered.

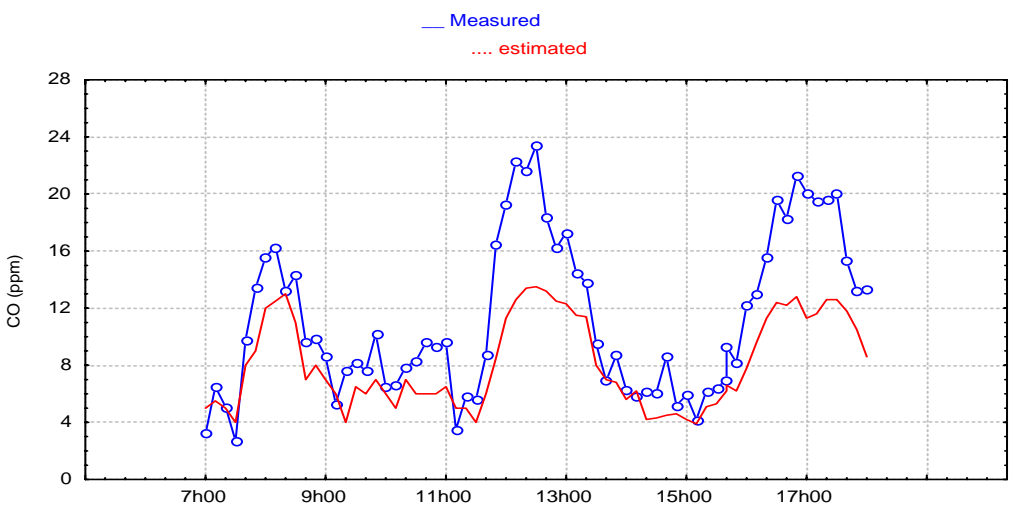

Figure 4 . Diurnal variation of estimated and measured pollution

With this increasing rate and keeping actual park without technical control, pollution will be unbearable near 2010 in Bejaia city.

\section{CONCLUSIONS}

Results of pollution measurements in Bejaia city and strong correlation with the number of vehicles confirms that automobile exhausts are the main source of urban air pollution. The calculated pollution according with emissions depending on vehicle age, fuel type and speed is comparable with the measured one. Very old vehicle (more than 20 years) exceed largely standard emissions and they represent more than $14 \%$ of the current park.

In order to improve air quality in urban cities, vehicles must be equipped with emission regulation system. Maintenance and technical control must be established in Algeria.

\section{REFERENCES}

1. Sarokin D. and Schulkin J. (1992) The role of pollution in large-scale population disturbance, Env. Sci. Technol., 26(9), 1694-1701.

2. Gramer L. and Chevreuil M. (1991) Automobile traffic: a source of PCBs to the atmosphere, Chemosphere, 23(6), $785-788$.

3. United States Environmental Protection Agency (1993) Automobiles and Carbon monoxide, EPA 400-F-92-005.

4. Jicha M. and Katolicky J. (2000) Dispersion of pollutants in street canyon under traffic induced flow and turbulence, Jour. for Environ. Monit. and asses., 65, 343 - 351.

5. European Guidelines for Air Quality (2002).

6. Alkama R. and Ourtirane K. (2004) Contribution of vehicle emissions to the air pollution in urban area, Dubai Int. Conf. Atm. Poll. February 21-23 Dubai, 102-106.

7. Michael M. and Walsh P. (2000) L'évolution des émissions des véhicules, document de travail de la conf. Europ. des ministres de tranports, Prague, 35-37. 